\title{
Hypoxaemia in adults in the post-anaesthesia care unit
}

M. Denise Daley BSc MD FRCPC,

Peter H. Norman BSc MD FRCPC, Maria E. Colmenares MD, Alan N. Sandler BSc MB ChB FRCPC
Continuous pulse oximetry was performed on 173 adulıs after general anaesthesia for elective inpatient surgery, throughout their post-anaesthesia care unit (PACU) stay. Supplemental oxygen was administered for $\geq 30 \mathrm{~min}$ after arrival and subsequently discontinued before discharge to the ward. The mean and minimum oxyhaemoglobin saturation $\left(\mathrm{SpO}_{2}\right)$ after discontinuing oxygen were lower than those values achieved during oxygen administration and preoperatively $(P<0.00 I)$. Al least one hypoxaemic episode $\left(\mathrm{SpO}_{2} \leq 90 \%\right.$ for $\left.\geq 15 \mathrm{sec}\right)$ occurred in 70 subjects (41\%) and 45 of these had a moderatesevere episode $\left(\mathrm{SpO}_{2} \geq 90 \%\right.$ for $\leq 2 \min$ or $\left.\mathrm{SpO}_{2} \leq 85 \%\right)$. The hypoxaemic episodes began $20 \pm 20$ min (range l-100; median 15) after discontinuing supplemental oxygen. Cyanosis was detected in only four of the 70 patients who desaturated. Factors associated with hypoxaemia were: ASA physical status class; surgical duration $\geq 90 \mathrm{~min}$; and preoperative mean $\mathrm{SpO}_{2}$ $<95 \%$. Factors not associated with hypoxaemia were: age, sex, \% ideal body wcight, smoking history, preoperative minimum $\mathrm{SpO}_{2}$, premedication and type of surgery. In conclusion, after discontinuing supplemental oxygen in the PACU, hypoxaemin was common, difficult to detect clinically, and associaled with ASA class, surgical duration and preoperative mean $\mathrm{SpO}_{2}$.

Nous avons monitoré continuellement la saturation artérielle en oxygène par oxymétrie pulsée en salle de réveil chez 173 adultes hospitalisés pour une intervention chirurgicale élective. Les patients respiraient un supplément d'oxygène pendant les 30 premières minutes de leur séjour en salle de réveil. Les valeurs minimales et moyennes en oxyhémoglobine enregistrées après

\section{Key words}

HYPOXIA: postoperative;

MEASUREMENT TECHNIQUES: pulse oximetry.

From the Department of Anaesthesia, Toronto General

Hospital, Toronto, Ontario, Canada.

Presented in part at: the 64th Congress of the International Anaesthesia Research Society, Honolulu, Hawaii, March 1990; and the Canadian Anaesthetists' Society 47th Annual Meeting, Vancouver, British Columbia, June 1990.

Address correspondence to: Dr. M. Denise Daley,

Department of Anaesthesia, Toronto General Hospital, 200

Elizabeth Street, Toronto, Ontario M5G 2C4.

Accepted for publication 12th April, 1991. l'arrêt du supplément en oxygène diminuaient en dessous de celles de la période précédente et de celles mesurées avant l'intervention chirurgicale. Au moins un épisode d'hypoxémie $\left(\mathrm{SpO}_{2} \leq 90 \%\right.$ duram au moins $\left.15 \mathrm{sec}\right)$ est survenu chez 70 patients $(41 \%)$ et l'hypoxémie était importante $\left(\mathrm{SpO}_{2} \leq 90 \%\right.$ pendant au moins 2 min ou $\mathrm{SpO}_{2} \geq 85 \%$ ) chez 45 d'entre eux. Elle apparaissait de I à 100 minutes après l'arrêt du supplément en oxygène, moyenne : 20 min, écart-rype : $20 \mathrm{~min}$, médiane : 15 min. Seuls quatre des patients qui désaturaient arboraient de la cyanose. Les facreurs associés à la survenue de l'hypoxémie étaient la classe ASA, un intervention chirurgicale de plus de 90 min et une $\mathrm{SpO}_{2}$ moyenne <95\% avant l'intervention. L'âge, le sexe, le poids des patients de même qu'une histoire de tabagisme, la $\mathrm{SpO}_{2}$ minimale préopératoire, la prémédication et le type d'intervention chirurgicale n' influençaient pas l'incidence d'hypoxémie en salle de réveil.

The immediate postoperative period is a potentially high-risk time for the occurrence of hypoxaemia. Consequently, supplemental oxygen is administered routinely in the initial post-anaesthesia care unit (PACU) stay in many institutions. For most patients, however, it is usually discontinued before discharge to the ward, based on clinical criteria such as being awake with normal vital signs and no respiratory distress. This practice assumes that patients who fulfill these criteria are no longer at risk of hypoxaemia. The validity of this assumption has not been established and the available literature suggests that it is not valid. ${ }^{1-5}$

Pulse oximetry, by providing accurate, ${ }^{6-8}$ objective measurements of oxygenation continuously and noninvasively is a useful technique for assessing the incidence of hypoxaemia in the PACU. In this study, it was employed in a diverse group of adults following general anaesthesia for elective inpatient surgery, throughout their PACU stay. Only those patients who usually have the supplemental oxygen discontinued before leaving the PACU were included. The incidence, severity, and time of onset of hypoxaemia and the relationship to possible associated factors were examined.

\section{Methods}

The study was performed in accordance with our institutional review board. Informed consent was obtained from 


\section{TABLE I Patient exclusion criteria}

Supplemental oxygen is not usually discontinued

- severe cardiopulmonary disease

- morbid obesily*

- thoracic, airway, intracranial surgery

Positive pressure ventilation is usually required

- major vascular surgery

- cardiac surgery

A disorder of respiratory regulation

- sleep apnea syndrome

- any neurological disease

Pulse oximetry may be an unreliable indicator of arterial oxygenation

- anaemia $\dagger$

- hypotension $\ddagger$

$* \geq 200 \%$ of the ideal body weight (IBW), as determined by the formulae: ${ }^{19}$

males: IBW $(\mathrm{kg})=$ height $(\mathrm{cm})-100$

females: IBW $(\mathbf{k g})=$ height $(\mathrm{cm})-105$

tHaemoglobin $<100 \mathrm{gl}^{-1}$ preoperatively or $<90 \mathrm{gl}^{-1}$ in the PACU.

\#Systolic blood pressure $<100 \mathrm{mmHg}$ preoperatively or $<90 \mathrm{mmHg}$ in the PACU.

174 subjects scheduled for elective inpatient surgery. The inclusion criteria were: ASA physical status class I-III; $\geqslant 40 \mathrm{yr}$ old; and surgery requiring general anaesthesia with tracheal intubation and positive pressure ventilation. The exclusion criteria are indicated in Table I.

The anaesthetic management was left to the discretion of the attending anaesthetist. The management in the PACU was also not actively influenced and the PACU staff were kept unaware of the results unless a moderatesevere hypoxaemic episode occurred (see below for definition). All patients were transferred from the operating room to the PACU breathing room air. Upon arrival in the PACU, supplemental oxygen was administered by a Hudson face mask at $10 \mathrm{~L} \cdot \mathrm{min}^{-1}$. This was removed after at least $30 \mathrm{~min}$ at the PACU nurse's discretion according to our usual PACU criteria (awake, with normal strength and vital signs, and no respiratory distress). Discharge was also determined by the PACU staff but required at least $45 \mathrm{~min}$ after removing the oxygen.

The subjects were monitored continuously with a pulse oximeter (Nellcor $\mathrm{N}-100^{(3)}$ ) from five min after arrival in the PACU until discharge. The alarms on the machine were turned off. The sensor was placed on a finger of the arm opposite the blood pressure cuff. An investigator constantly observed the patient and monitoring apparatus to ensure the presence of an adequate pulse signal and to eliminate artifacts produced by such events as patient movement or sensor dislodgement. The oxyhaemoglobin saturation $\left(\mathrm{SpO}_{2}\right)$ was recorded manually every five min and any time it decreased below the preceding five min value. The five min values were used to calculate the mean $\mathrm{SpO}_{2}$ and all were used to determine the minimum
$\mathrm{SpO}_{2}$. A hypoxaemic episode was defined as an $\mathrm{SpO}_{2}$ $\leq 90 \%$ lasting at least $15 \mathrm{sec}$. During these episodes, the respiratory rate $(R R)$, respiratory pattern, presence or absence of central cyanosis, minimum $\mathrm{SpO}_{2}$, duration of episode and level of consciousness (LOC) were recorded. The respiratory pattern was determined by visual inspection of the subjects' chest and abdominal movements. The LOC was graded as: 1 = fully awake; 2 = drowsy/asleep but easily aroused; or 3 = asleep and difficult to arouse. A moderate-severe episode was defined as an $\mathrm{SpO}_{2} \leq 90 \%$ for at least two min or an $\mathrm{SpO}_{2} \leq 85 \%$ for any duration. When these occurred, the PACU staff were notified, the patient was stimulated and supplemental oxygen resumed. The oxygen was administered for the remainder of the PACU stay and continued until the next day. Supplemental oxygen was also administered at the time of discharge from the PACU if, in the ten $\min$ before discharge, any hypoxaemic episode occurred or the $\mathrm{SpO}_{2}$ was consistently $91-92 \%$. The blood pressure, RR and LOC were also recorded routinely every $15 \mathrm{~min}$ in all subjects. The latter two measurements were performed while the patients were undisturbed, before the blood pressure was obtained.

Preoperative pulse oximetry was performed on 116 of the subjects for $15 \mathrm{~min}$ while resting quietly the night before surgery. The $\mathrm{SpO}_{2}$ was recorded at one-minute intervals and any time it decreased below the preceding one-min value. The mean preoperative $\mathrm{SpO}_{2}$ was determined from the one-minute values and the minimum using all values. If the preoperative $\mathrm{SpO}_{2}$ was $<91 \%$ at any time the patient was excluded from the study. This resulted in one patient being excluded, leaving a total of 173 subjects.

After the PACU data were collected, the patients' charts were reviewed to obtain information regarding factors which may be associated with the occurrence of hypoxaemia.

The data are presented as mean \pm SD and range unless otherwise indicated. One-way repeated measures ANOVA was used to analyze the mean and minimum $\mathrm{SpO}_{2}$ values preoperatively, while receiving supplemental oxygen in the PACU and after its removal. Post-hoc analyses using univariate F-tests were performed to compare the $\mathrm{SpO}_{2}$ values at individual times. The fractions of desaturating and non-desaturating patients with a $R R<10 \mathrm{bpm}$ were compared by the Fisher exact test. The potential associated factors were examined by multiple logistic regression analysis. The analysis of the age group data from the Moller et al. ${ }^{5}$ study reported in the Discussion was performed with Chi-square tests. All analyses were performed using the Systat ${ }^{\oplus}$ and Systat-Logit ${ }^{\circledR}$ (Systat, Evanston, Illinois) computer software programs. A $P$ value $<0.05$ was considered statistically significant for all the analyses except the F-tests. For these, $P<0.001$ 


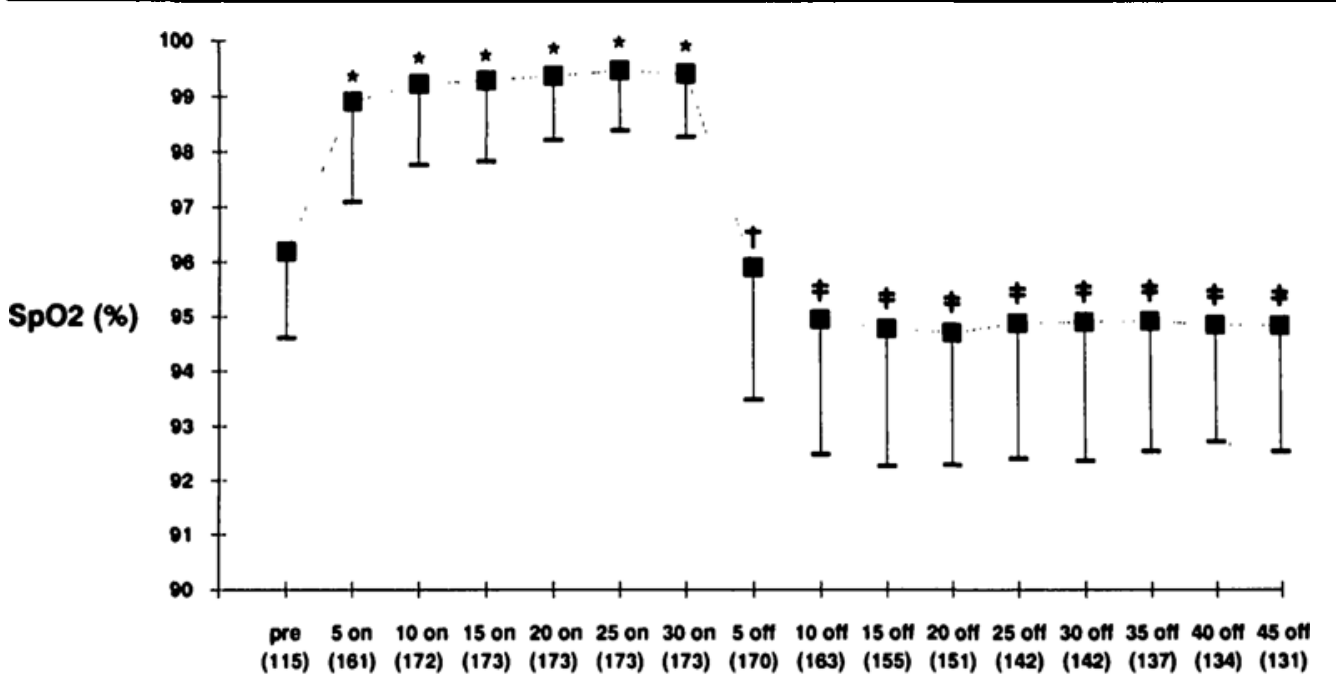

TIME (min)

FIGURE 1 A verage mean $\mathrm{SpO}_{2}$ (mean $\pm \mathrm{SD}$ ) preoperatively (preop); during the first 30 min of supplemental oxygen administration in the PACU ( 5 on -30 on); and during the first $45 \mathrm{~min}$ after discontinuation of the oxygen therapy ( 5 off -45 off). The numbers in brackets indicate the number of patients included in the calculation of the $\mathrm{SpO}_{2}$ at each time interval. $* P<0.001$ vs preop and 5 off -45 off. $\dagger P<0.001$ vs 10 off -45 off. $¥ P<0.001$ vs preop.

was required, using the Bonferroni correction due to the multiple comparisons performed.

\section{Results}

Of the 173 subjects examined in this study, 77 were male and 96 were female. The mean age was $59.3 \pm 11.7 \mathrm{yr}$ (40-92) and \% ideal body weight was $119 \pm 25$ (73-189). All patients except one received a "balanced" anaesthetic, with intravenous agents, $\mathrm{N}_{2} \mathrm{O}(60-70 \%)$ and isoflurane or halothane. The exception had a narcoticbased anaesthetic with no potent inhalational agents. No subjects were withdrawn from the study due to anaemia or hypotension in the PACU.

The subjects were monitored in the PACU for $57 \pm 27$ min (30-170) while receiving supplemental oxygen and $49 \pm 27$ min (5-130) after its removal. An $\mathrm{SpO}_{2}$ value was not obtainable in 12 subjects at 5 min after arrival in the PACU and in one subject at 10 min after arrival, due to patient movement or peripheral vasoconstriction. In 131 patients, $\mathrm{SpO}_{2}$ values were recorded for at least $45 \mathrm{~min}$ after discontinuing the supplemental oxygen. For the other 42 subjects, values were not available for the entire $45 \mathrm{~min}$ because the supplemental oxygen was resumed due to the occurrence of a moderate-severe hypoxaemic episode. The number of subjects included in the data analysis at each 5 min interval is indicated in Figure 1.

The average mean and minimum $\mathrm{SpO}_{2}$ values preoperatively, while receiving supplemental oxygen in the PACU and after its discontinuation, are shown in Figures
1 and 2. The minimum $\mathrm{SpO}_{2}$ while receiving supplemental oxygen occurred at $21 \pm 21 \mathrm{~min}(5-168$; median 15) after arrival in the PACU. The minimum $\mathrm{SpO}_{2}$ while off oxygen occurred at $26 \pm 18 \mathrm{~min}(2-110$; median 23$)$ after discontinuing the supplemental oxygen and $82 \pm 32 \mathrm{~min}$ (32-218; median 75) after arrival in the PACU.

At least one hypoxaemic episode occurred in 70 (41\%) of the subjects. A moderate-severe episode occurred in 45 of these desaturators ( $64 \%$ of those who desaturated; $26 \%$ of all patients). Supplemental oxygen was administered at discharge to the ward in $59(34 \%)$ of all subjects (including the $26 \%$ with a moderate-severe episode). All hypoxaemic episodes occurred after the supplemental oxygen was discontinued. Every moderate-severe episode was managed successfully by resuming the oxygen therapy. The hypoxaemic episodes started $20 \pm 20 \mathrm{~min}$ (1-100; median 15) after discontinuing the supplemental oxygen and $83 \pm 31$ min (32-185; median 80 ) after entering the PACU. The number of patients who started to desaturate during each 5 min epoch is shown in Figure 3.

For those subjects who desaturated, the number of hypoxaemic episodes per patient was $5 \pm 5$ (1-24; median 3 ), with mean and maximum durations of $93 \pm 78$ $\sec (15-310$; median 70) and $146 \pm 96 \mathrm{sec}$ (15-357; median 140), respectively. The minimum $\mathrm{SpO}_{2}$ during the episodes was $86.8 \pm 2.1 \%$ (81-90; median 87$)$. These values probably underestimate the number and severity of the episodes that would have been attained without the intervention of this study because the supplemental 


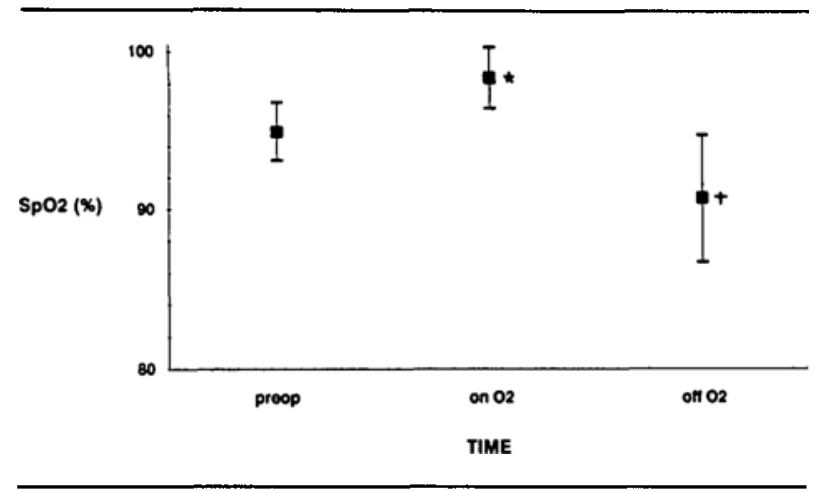

FIGURE 2 Average minimum $\mathrm{SpO}_{2}$ (mean $\pm \mathrm{SD}$ ) preoperatively (preop); while receiving supplemental oxygen in the PACU (on $\mathrm{O}_{2}$ ); and after discontinuation of the supplemental oxygen (off $\mathrm{O}_{2}$ ). ${ }^{* P}<$ 0.001 vs preop and off $\mathrm{O}_{2} . \dagger P<0.001$ vs preop.

oxygen was resumed immediately when a moderatesevere episode occurred. The RR was $<10 \mathrm{bpm}(6-8$ bpm) in seven patients during at least one of their hypoxaemic episodes. Four patients who did nol desaturate also had at least one recorded $R R<10 \mathrm{bpm}$ during the routine assessment of RR every $15 \mathrm{~min}$. These fractions ( $7 / 70$ vs $4 / 103$ ) were not significantly different. Respiratory pattern abnormalities were present in 36 patients while hypoxaemic, including: partial upper airway obstruction (21); forced expiration (6); shallow respirations (5); and Cheyne-Stokes breathing (4). Since the presence or absence of these abnormalities was only recorded by the investigator during hypoxaemic episodes, it is not known whether they occurred in the same patients when they were not hypoxaemic or in those subjects who did not desaturate. All patients except one had a LOC score of 2 while hypoxaemic. The exception had a score of 1 . However, all patients, whether hypoxaemic or not, had a score of 2 for the majority of their PACU stay. Cyanosis was detected by the investigator in only four subjects during their hypoxaemic episodes. It was noted by the attending PACU nurse in only one patient.

Factors associated with the occurrence of at least one hypoxaemic episode are shown in Table II. Those not associated were: age (40-64 yr 49/114; $\geq 65$ yr 21/59); sex (male 32/77; female 38/96); smoking history (current 12/31; past 27/51; never 31/91); \% ideal body weight $(<120 \% 31 / 97 ; \geq 120 \% 39 / 76)$; premedication (yes $52 / 123$; no 18/50); surgical site (peripheral 28/59; perineal 5/33; lower abdominal 12/35; upper abdominal 25/46); and preoperative minimum $\mathrm{SpO}_{2}(<95 \% 25 / 45 ; \geq 95 \%$ 19/68). The lack of an association persisted when the variables were redefined as: premedication - narcotic vs benzodiazepine vs none; smoking history - current vs past and never or current and past vs never; and surgical site - peripheral and perineal vs lower abdominal vs upper

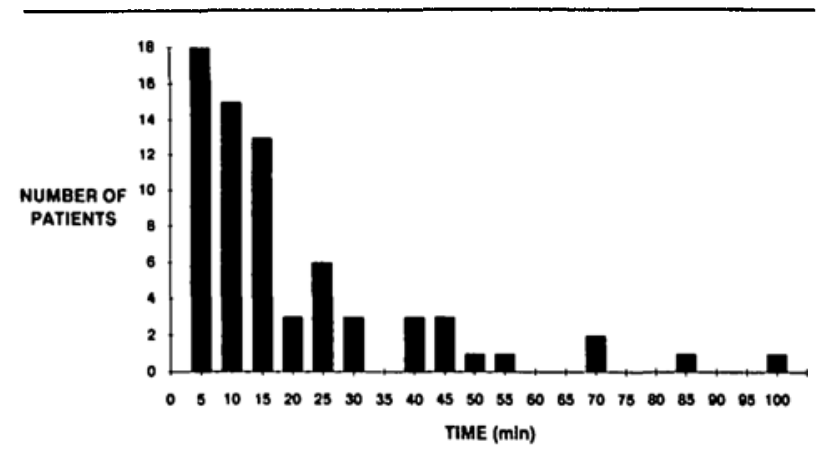

FIGURE 3 The number of patients who slarted to desaturate during each five-min epoch after discontinuation of the supplemental oxygen in the PACU.

TABLE II Factors associated with hypoxaemia

\begin{tabular}{|c|c|c|c|}
\hline & $\begin{array}{l}\text { Number of } \\
\text { patients }\end{array}$ & $\begin{array}{l}\text { \% parients } \\
\text { with } \geq 1 \\
\text { hypoxaemic } \\
\text { episode }\end{array}$ & $P$ value \\
\hline \multicolumn{4}{|c|}{ ASA physical status class } \\
\hline I & 39 & 26 & $<0.01$ \\
\hline II & 104 & 37 & \\
\hline III & 30 & 73 & \\
\hline \multicolumn{4}{|c|}{ Surgical duration } \\
\hline$<90$ min & 77 & 27 & $<0.05$ \\
\hline$\geqslant 90 \mathrm{~min}$ & 96 & 51 & \\
\hline \multicolumn{4}{|c|}{ Preoperative mean $\mathrm{SpO}_{2}$} \\
\hline$\geqslant 95 \%$ & 98 & 32 & $<0.01$ \\
\hline$<95 \%$ & 15 & 87 & \\
\hline
\end{tabular}

abdominal or peripheral and perineal vs lower and upper abdominal.

\section{Discussion}

The potential for hypoxaemia during the early recovery period following general anaesthesia has been known for decades. In the 1960's and early 1970's, several studies reported an average decrease in $\mathrm{PaO}_{2}$ in the first two hours after surgery of $0.9-2.4 \mathrm{kPa}(7-18 \mathrm{mmHg})$, obtained by one to three discrete blood gas analyses per subject. ${ }^{9-10}$ More recently, pulse oximetry has been used to assess oxygenation in the PACU. Due to its continuous and noninvasive qualities, the pulse oximeter is well suited to monitoring large numbers of patients over time.

Previous PACU pulse oximetry studies have usually concentrated on one of two time periods: at arrival in the PACU; and during the PACU stay. The current study is an example of the latter because five minutes elapsed after arrival in the PACU (while subjects breathed supple- 
TABLE III Previous pulse oximetry studies involving adults in the PACU

\begin{tabular}{|c|c|c|c|c|c|c|c|c|}
\hline Subjects & Monitoring & Age & $\begin{array}{l}\text { ASA } \\
\text { class }\end{array}$ & $\begin{array}{l}\text { In-or out- } \\
\text { patients }\end{array}$ & $\begin{array}{l}\text { Type of } \\
\text { anaesthesia }\end{array}$ & $\begin{array}{l}\text { Type of } \\
\text { surgery }\end{array}$ & Incidence of hypoxaemia & Authors \\
\hline 161 & Intermittent & $\begin{array}{l}\text { Paediatric } \\
\text { and adult }\end{array}$ & I-III & In- and out- & General & $\begin{array}{l}\text { Various } \\
\text { (104 peripheral) }\end{array}$ & $0.6 \%\left(\mathrm{SpO}_{2}<90 \%\right)^{*}$ & $\begin{array}{l}\text { Hudes ET } \\
\text { ef al. }{ }^{14}\end{array}$ \\
\hline 164 & Continuous & Adult & $I-I I$ & Out- & General & $\begin{array}{l}\text { Mostly } \\
\text { gynecological }\end{array}$ & $\begin{array}{l}7 \%\left(\mathrm{SpO}_{2} \leq 92 \%\right) \\
4 \%\left(\mathrm{SpO}_{2} \leq 90 \%\right)\end{array}$ & $\begin{array}{l}\text { Murray RS } \\
\text { et al.' }\end{array}$ \\
\hline 10 & Continuous & Adult & 1 & NA & General & $\begin{array}{l}\text { Gynecological } \\
\text { and peripheral }\end{array}$ & $\begin{array}{l}\mathrm{NA} \\
\text { (mean minimum } \mathrm{SpO}_{2} 90 \pm 3 \% \text { ) }\end{array}$ & Lim Gef al..$^{2}$ \\
\hline 241 & Intermittent & NA & $1-I V$ & $\begin{array}{l}147 \text { in- } \\
92 \text { out- }\end{array}$ & $\begin{array}{l}165 \text { general } \\
76 \text { regional }\end{array}$ & Various & $\begin{array}{l}14 \% \text { inpatients }\left(\mathrm{SpO}_{2} \leq 90 \%\right) \\
1 \% \text { outpatients }\left(\mathrm{SpO}_{2} \leq 90 \%\right)\end{array}$ & $\begin{array}{l}\text { Morris RW } \\
\text { el al. }{ }^{3}\end{array}$ \\
\hline 101 & Continuous & $\begin{array}{l}\text { Paediatric } \\
\text { and adult }\end{array}$ & l-IV & NA & NA & Various & $18 \%\left(\mathrm{SpO}_{2}<90 \%\right)$ & $\begin{array}{l}\text { Nakalsuka M } \\
\text { et al. }{ }^{4}\end{array}$ \\
\hline 200 & Continuous & Adult & I-IV & NA & $\begin{array}{l}\text { General and } \\
\text { regional }\end{array}$ & Various & $55 \%\left(\mathrm{SpO}_{2} \leq 90 \%\right)$ & $\begin{array}{l}\text { Moller JT } \\
\text { ef al. }\end{array}$ \\
\hline
\end{tabular}

NA = information not supplied by authors.

"Data obtained only while patients received supplemental oxygen.

mental oxygen) before monitoring was initiated. Although no studies have addressed the issue, it is probably appropriate to consider the two time periods as separate entities with potentially different causes and frequencies of hypoxaemia. For example, diffusion hypoxaemia and post-hyperventilation hypoxia may be important at the time of arrival in the PACU, but not during the later PACU stay. Several studies have reported hypoxaemia as a frequent occurrence on arrival in the PACU. Defining hypoxaemia as an $\mathrm{SpO}_{2}<90 \%$, incidences of $19-61 \%$ have been noted in adult or teenager-adult populations ${ }^{11-13}$ The incidence during the PACU stay has been less extensively studied. Previous pulse oximetry studies which examined this period in adults are summarized (Table III).

In this study, hypoxaemia was not detected during supplemental oxygen administration. This supports the usual clinical assumption and agrees with most previous studies. ${ }^{14}$ However, Moller et al. ${ }^{5}$ reported at least one hypoxaemic episode in $32 \%$ of a diverse group of adults. This may have been due to their use of nasal oxygen at $\geq 3$ $\mathrm{L} \cdot \mathrm{min}^{-1}$. Williams et al., ${ }^{15}$ comparing different modes and rates of administration of supplemental oxygen in the PACU, noted a mean $\mathrm{PaO}_{2}$ of $12.1 \mathrm{kPa}(91 \mathrm{mmHg})$ with oxygen at $3 \mathrm{~L} \cdot \mathrm{min}^{-1}$ by nasal cannula and $21.5 \mathrm{kPa}(162$ $\mathrm{mmHg}$ ) with $9 \mathrm{~L} \cdot \mathrm{min}^{-1}$ by Hudson face mask.

Analyzing the average mean $\mathrm{SpO}_{2}$ over time revealed an increase above the preoperative value during oxygen therapy, a decrease to a level similar to that preoperatively at five minutes after discontinuation of the oxygen and a further decrease below the preoperative value at $10 \mathrm{~min}$ off oxygen and later. The mean $\mathrm{SpO}_{2}$ values at 10 to 45 min off oxygen were similar. However, it must be noted that throughout the period off supplemental oxygen, progressively more patients were removed from the study due to moderate-severe hypoxaemic episodes. Therefore the average mean $\mathrm{SpO}_{2}$ values at these times did not include the more severe desaturators and are probably higher than they would have been without the intervention of this study. The time course noted by Lim et al. ${ }^{2}$ showing a progressive decrease in $\mathrm{SpO}_{2}$ in the first hour after discontinuation of the supplemental oxygen and then a progressive increase, may more closely approximate the natural, undisturbed situation (at least in healthy adults after gynaecological or peripheral surgery).

At least one hypoxaemic episode occurred in $41 \%$ of the subjects after removal of the supplemental oxygen and $64 \%$ of these had a moderate-severe episode. This incidence is higher than we expected, especially since we included only those patients whom we usually considered to be at low risk of desaturating. It is also higher than most of the previous studies in this field. This disparity may be attributed to the use of only intermittent monitoring, ${ }^{3}$ selection of only ASA I-II patients, ' and/or inclusion of younger subjects ${ }^{1-4}$ in these other studies. Our incidence is closer to, although slightly lower than, the 55\% reported by Moller et al. ${ }^{5}$ However, a direct comparison with our data is not appropriate since this $55 \%$ included an $8 \%$ incidence of hypoxaemia on arrival in the PACU and a $32 \%$ incidence while receiving supplemental oxygen (as discussed above).

The time of onset of hypoxaemic episodes was variable, with a mean of $20 \mathrm{~min}$ and median of $15 \mathrm{~min}$ after removal of the supplemental oxygen. For most patients the onset was within the first $30 \mathrm{~min}$ while off oxygen but in six cases the episodes started after $45 \mathrm{~min}$. Since discharge to the ward was permitted at $\geq 45 \mathrm{~min}$ after discontinuation of the supplemental oxygen, our inci- 
dence of hypoxaemia after this time may be an underestimate. Studies using more extended periods of monitoring are required to address this issue.

Cyanosis was detected in only four $(6 \%)$ of the desaturating patients. This is similar to the $5 \%$ previously reported by Moller's group ${ }^{5}$ and supports the classical observations of Comroe and Botelho that "visual impressions of cyanosis are unreliable." 16

Although the aetiology of the hypoxaemic episodes was not directly addressed in this study, several observations were noted which may aid in designing future studies to assess this. The RR was $<10 \mathrm{bpm}$ in only $10 \%$ of the patients when hypoxaemic which was similar to the incidence in non-hypoxaemic patients. This suggests that a low RR per se is an insensitive and nonspecific predictor of hypoxaemia. The aetiological role of hypoventilation, however, cannot be assessed without concomitant measurement of tidal volumes. Respiratory pattern abnormalities, especially partial upper airway obstruction, were noted frequently during the hypoxaemic episodes. However, because of the subjective method of assessment and the lack of information whether such abnormalities occurred at other times, it is not appropriate to suggest a causal relationship. Continuous objective respiratory pattern monitoring is necessary to address this issue properly. Although our institution's official criteria for discontinuation of supplemental oxygen required the patients to be awake, all subjects had a LOC score of 2 (drowsy/asleep but easily aroused) for the majority of their PACU stay. The LOC score therefore did not differ between subjects during the hypoxaemic episodes and the same patients when not hypoxaemic or the nondesaturating patients. However, the scale used to assess this was quite gross, containing only three categories. A scale with more categories may have detected more subtle differences in LOC.

Factors associated with the occurrence of at least one episode of hypoxaemia were: ASA physical status class; surgical duration $\geq 90 \mathrm{~min}$; and preoperative mean $\mathrm{SpO}_{2}$ $<95 \%$. The association with ASA class and surgical duration support the results of previous studies. ${ }^{3,4}$ The association with the preoperative $\mathrm{SpO}_{2}$ is not surprising, but differs from one previous study ' which examined this. That study, however, examined only healthy outpatients, all of whom had a preoperative $\mathrm{SpO}_{2} \geq 95 \%$.

Factors not associated with the occurrence of hypoxaemia were: age, sex, \% ideal body weight, smoking history, preoperative minimum $\mathrm{SpO}_{2}$, premedication, and surgical site. The lack of association with sex, ideal body weight, premedication and surgical site has been noted in most previous studies. ${ }^{4.5}$ Morris et al. ${ }^{3}$ however, reported obesity and body cavity surgery as predic- tive factors. Their statistical analysis may have accounted for the discrepancy because they: used no method to compensate for relationships between associated factors; and accepted a $P$ value $<0.05$ for significance despite performing multiple comparisons, which would more appropriately require a lower $P$ value (using the Bonferroni correction). The association with age has varied in previous studies. The association noted in some of these may be explained by differences in the age groups examined. For example, closer analysis of the Moller $e t$ al. ${ }^{5}$ data reveals that although the 18-39 yr group had a lower incidence of hypoxaemia than those $\geq 40 \mathrm{yr}$, there was no difference between the 40-60 yr and $>60 \mathrm{yr}$ groups, which are similar to the ages examined in the current study. Similarly, Morris's group ${ }^{3}$ reported an association with age, but only examined the $\leq 40 \mathrm{yr}$ and $>40 \mathrm{yr}$ groups. This suggests that although adults $<40 \mathrm{yr}$ have a lower risk of developing hypoxaemia than those $>40 \mathrm{yr}$, age beyond $40 \mathrm{yr}$ is not an important predictive factor. The role of a smoking history is also controversial. This may be at least partly due to differences in the severity of chronic lung disease between the populations studied. In the current study, for example, subjects with severe lung disease were excluded. In addition, studies failing to distinguish between hypoxaemia on arrival in the PACU and during the PACU stay when assessing potential risk factors ${ }^{4,5}$ are difficult to interpret, as discussed above. The association noted by Nakatsuka's group ${ }^{4}$ is also questionable because their statistical analysis has the same deficiencies as the Morris et al. ${ }^{3}$ study.

Although the pulse oximeter may have limitations, especially in the presence of peripheral vasoconstriction, it appeared to function well. It failed to provide data in just 12 patients for only the first five to ten minutes after arrival in the PACU. The instrument used (Nellcor $\left.\mathrm{N}-100^{\circledR}\right)$ has an accuracy of approximately $\pm 2 \%$ in the $\mathrm{SpO}_{2}$ range examined in this study. ${ }^{7,8} \mathrm{We}$ acknowledge that a more sophisticated model with such features as a plethysmographic display, EKG synchronization and improved software, would have been preferable.

The clinical importance of the hypoxaemic episodes detected in this study is unknown. The occurrence of moderate-severe episodes in $26 \%$ of the subjects is a potential concern and most clinicians would consider similar findings during the intraoperative period to be unacceptable. However, there is no evidence to suggest that such episodes in the PACU period effect morbidity or mortality. To the contrary, evidence of similar episodes during sleep in normal healthy adults suggests that they may simply reflect respiratory events occurring in normal sleep. Block's group, ${ }^{17,18}$ for example, have noted at 
least one episode of $\mathrm{SpO}_{2}<90 \%$ in $43 \%$ of adult males and $40 \%$ of postmenopausal females during nocturnal sleep. Further investigations including preoperative monitoring during sleep and outcome analysis will be necessary to assess the significance of postoperative hypoxaemia.

In conclusion, $41 \%$ of the adult population studied had at least one episode of hypoxaemia during their PACU stay. A moderate-severe episode occurred in more than $50 \%$ of the desaturating subjects. Cyanosis was detected in only $6 \%$ of the patients while hypoxaemic. ASA physical status class, preoperative mean $\mathrm{SpO}_{2}$ and surgical duration were associated with the occurrence of hypoxaemia.

\section{References}

I Murray RS, Raemer DB, Morris RW. Supplemental oxygen after ambulatory surgical procedures. Anesth Analg 1988; 67: 967-70.

2 Lim G, Skinner MI, Rose A, Knill RL. Delayed hypoxaemia during recovery from anaesthesia (Abstract). Can J Anaesth 1988; 35: S72.

3 Morris RW, Buschman A, Warren DL, Philip JH, Raemer $D B$. The prevalence of hypoxemia detected by pulse oximetry during recovery from anesthesia. J Clin Monit 1988; 4: 16-20.

4 Nakatsuka $M$, Bolling $D$. Incidence of postoperative hypoxemia in the recovery room detected by the pulse oximeter (Abstract). Anesth Analg 1989; 68: S209.

5 Moller JT, Wittrup M, Johansen $S H$. Hypoxemia in the postanesthesia care unit: an observer study. Anesthesiology 1990; 73: 890-5.

6 Yelderman $M$, New $W$. Evaluation of pulse oximetry. Anesthesiology 1983; 59: 349-52.

7 Taylor $M B$, Whitman JC. The accuracy of pulse oximeters: a comparative clinical evaluation of five oximeters. Anaesthesia 1988; 43: 229-32.

8 Nickerson BG, Sarkisian C. Tremper $K$. Bias and precision of pulse oximeters and arterial oximeters. Chest 1988; 93: 515-7.

9 Marshall BE, Millar RA. Some factors influencing postoperative hypoxaemia. Anaesthesia 1965; 20: 408-27.

10 Boutros $A R$, Weisel $M$. Comparison of the effects of three anaesthetic techniques on patients with severe pulmonary obstructive disease. Can J Anaesth 1971; 18: 286-92.

11 Tyler IL, Tantisira B, Winter PM, Motoyama EK. Continuous monitoring of arterial oxygen saturation with pulse oximetry during transfer to the recovery room. Anesth Analg 1985; 64: 1108-12.

12 Meiklejohn BH, Smith G, Elling AE, Hindocha N. Arterial oxygen desaturaion during postoperative transportation: the influence of operative site. Anaesthesia 1987; 42: 1313-5.
13 Bissonnelte $B$, Scolt $A A$. Arterial oxygen saturation in adults during transport from the operating room to the recovery room (Abstract). Can J Anaesth 1987; 34: S86-7.

14 Hudes ET, Maranas, Hirano GM, Scolt AC, Ho K. Recovery room oxygenation: a comparison of nasal catheters and 40 per cent oxygen masks. Can J Anaesth 1989; 36: 20-4.

15 Williams $A B$, Jones $P L$, Mapleson WW. A comparison of oxygen therapy devices used in the postoperative recovery period. Anaesthesia 1988; 43: 131-5.

16 Comroe JH, Botelho $S$. The unreliability of cyanosis in the recognition of arterial anoxemia. Am J Med Sci 1947; 214: $1-6$.

17 Block AJ. Boysen PG, Wynne JW. Hunt LA. Sleep apnea, hypopnea and oxygen desaturation in normal subjects: a strong male predominance. N Engl J Med 1979; 300: 513-7.

18 Block AJ, Wynne JW, Boysen PG. Sleep-disordered breathing and nocturnal oxygen desaturation in postmenopausal women. Am J Med 1980; 69: 75-9.

19 Yao FF. Morbid obesity. In: Yao FF, Artusio JF (Eds.). Anesthesiology: Problem - Oriented Patient Management, New York: J. B. Lippincott Company, 1983: $441-52$. 